Fernanda A. Alberto, Urânia G. Santos, Helena R. G. Q. Schwitzky, Zeila P. C. Togashi, Célia Lopes, Ivanilde Zamae

NEPEM - Secretaria Municipal de Saúde de Marília. Endereço: Av. República, 770, Banzato, CEP 17512-ooo, Marília, SP, Brasil.

E-mail: dstasmhs@eterra.com.br

Em Marília-SP, a Secretaria Municipal de Saúde iniciou a implementação do projeto "Saúde e Prevenção nas Escolas - SPE” em 2007, motivada pela tendência de crescimento do HIV entre jovens de 13 a 19 anos. Em parceria com a Diretoria Regional de Ensino de Marília, selecionou seis (6) escolas estaduais (20\% da rede estadual no município) de nível médio para iniciar as atividades propostas pelos Ministérios da Saúde e Educação no SPE. Ocorreram encontros nestas escolas e nos serviços de saúde de referência para aquelas comunidades escolares e, por fim, uma Oficina de Formação de Educadores foi realizada. As seis escolas construíram projetos, que vêm sendo executados em 2008. Atualmente, outras 16 escolas de nível médio da Rede Estadual estão sendo capacitadas para desenvolver o Projeto, totalizando 8o\% da Rede de Ensino. A implantação do SPE em Marília proporcionou uma nova integração para Saúde e Educação, um desafio diante dos processos de trabalho tão distintos desses setores. Destaca-se também o potencial do Projeto em mobilizar e efetivar o controle social jovem, por meio do investimento em políticas que promovam a cidadania e o ativismo entre adolescentes.

\title{
Saúde e Educação: um Encontro de Saberes para a Implementação do Projeto "Saúde e Prevenção nas Escolas"
}

